\title{
CHIRIGUANOS E INCAS: APUNTES PARA UN ESTUDIO DE LOS GRUPOS MARGINALES DEL TAHUANTINSUYO
}

\author{
Luis Millones
}

\section{INTRODUCCIÓN}

Empecemos por reconocer la antigüedad del tema que ahora tratamos. Justamente, revisar los principales estudios acerca de los chiriguanos proveerá material para discutirlo largamente a pesar de la indudable seriedad con que Metraux (1929, 1931, 1932, 1963), Nordenskiöld (1917) y Gandía (1929) han intentado una visualización general de la problemática que envuelve las investigaciones sobre esta tribu. Los historiadores no han podido aportar una interpretación de la documentación ya impresa que sobre ellos existe desde el siglo XVI a nuestros días, apenas si han repetido la información de las crónicas y viajeros sujetos a las obvias contradicciones de su época. Los antropólogos han trabajado con el escaso remanente humano, hoy situado entre los ríos Grande y Pilcomayo, donde las vinculaciones de nuestro grupo con los Choné hace realmente difícil diferenciar los rasgos culturales de ambas tribus (Lehmann-Nitsche 1924: 81). Todo esto sin tomar en cuenta que su forzada participación en la Guerra del Chaco (Céspedes, circa 1933) transformó violentamente los patrones de conducta nativos.

Lo extraño es que los chiriguanos o Ava Chahuanco, como ellos prefieren llamarse, no son un grupo nuevo en la historia cultural de Sudamérica. Su descripción es una de las primeras: Álvar Núñez Cabeza de Baca (1922: 322) dio la noticia del conocido viaje de un grupo de guaraníes hacia los bordes del Tahuantinsuyo. En esta "correría" participó el ya famoso Alejo García, un soldado de la armada de Solís que hacia el año 1526 acompañara a dichos indios. Su magro botín (Díaz de Guzmán 1962: 47) sirvió, sin embargo, para enrumbar la búsqueda del Dorado hacia el Oeste del Río de la Plata, sirviendo su aventura como piedra de toque a toda investigación sobre los chiriguanos. No obstante, dado que Núñez Cabeza de Vaca no usó jamás el nombre de "chiriguanos" la decantada importancia de la "invasión dirigida por Alejo García" deriva casi íntegramente de párrafos entresacados de La Argentina, un libro escrito en 1612, es decir casi un siglo de tal aventura.

La historiografía posterior se enfrascó en discutir si fue Pizarro o García (Nordenskiöld, 1917: 121) quien llegó primero al Perú o si fueron ellos los que invadieron a los incas o los incas quienes se apoderaron de su territorio (Jeans 1917: 482-484) e incluso Metraux en el Handbook se cuida muy bien de enumerar la cantidad de invasiones adjudicando a nuestro Alejo García le jefatura de la cuarta (1963: 465), clasificación que se repite sin variantes en casi todos los manuales contemporáneos (Véase Pericot y García, 1962: 1013). 
Mi propósito en este trabajo es buscar un nuevo esquema de preguntas que integre al menos los trabajos de diversos especialistas. Preguntas que incluso pueden partir de la vieja documentación etnohistórica o de la recolección arqueológica (Outes 1909) pero que al menos rompan el círculo vicioso en que se han quedado encerrados los estudios de este importante grupo humano.

\section{Los Chiriguanos: BREve Revisión DE LOS ES- TUDIOS TRADICIONALES}

Resulta interesante comprobar como los chiriguanos nunca han sido estudiados haciendo abstracción de su pretendida dependencia andina. Ellos, "salvajes" siempre que muestren un rasgo cultural que disuene con su necesaria ignorancia tiene que tratarse de un "préstamo cultural", comercio o cualquier clase de influencia. Al igual que los Antis del Este o la gente de Paria en el Norte, su nivel cultural fluctúa en razón de su cercanía a las altas culturas de los Andes. El culto al Sol en la mitología Chiriguana (Lehmann-Nitsche 1924: 84) o las flautas de pan desenterradas en Tarija (Metraux 1963: 468) pueden ser ejemplos del funcionamiento de este prejuicio. En ambos casos se asume de antemano que el contacto con los incas fue la causa de los mencionados hallazgos.

No estamos afrontando una situación especialmente nueva, a principios del siglo XVII cuando Garcilaso de la Vega escribía sus Comentarios Reales desde ya proclamaba claramente la idea imperial cuzqueña: "Otras naciones hubo como son los chiriguanas y los del cabo de Pasau (que de septentrión a mediodía son estas dos provincias los términos del Perú), que no tuvieron ni tienen inclinación de adorar cosa alguna baja ni alta, ni por el interés ni por el miedo, sino que en todo vivían y viven hoy como bestias y peores, porque no llegó a ellos la doctrina y la enseñanza de los Reynos Incas" (1960: 90). Dentro de la cuidadosa formación renacentista del cronista mestizo -ávido lector de Plutarco- funcionaban los patrones romanos como esquemas de la sociedad de sus abuelos maternos, el imperio y los bárbaros de la frontera. Nada faltaba para la fantástica comparación que ha seguido funcionando en la mentalidad de los investigadores contemporáneos: las calzadas romanas, el emperador, las vírgenes del sol y el ataque de gente inferior que desde las fronteras amenazaba la Roma Sudamericana. Cronistas tardíos repetirán la versión y aunque no siempre triunfaran las armas imperiales, en todo caso basta mantener alejados a los bárbaros. Claro, no podían faltar las fechas, el Handbook recoge de Garcilaso los años que van desde 1471 a 1476 durante el gobierno de un Inca Yupanqui, en igual tiempo se habría efectuado el ataque de las hordas chaqueñas que mal que bien fueron sin demasiadas complicaciones las fortalezas de Cuzcotuyo (Sarmiento de Gamboa 1947: 248) que en el mapa diseñado por Nordenskiöld aparecen con los nombres modernos de Incallacta e Incahuasi. Su presencia explicaría la necesidad de proteger las fronteras del sud-oeste del Tahuantinsuyo y con sus guarniciones y mitimaes aparecen justificadas las prolongaciones andinas hacia el Chaco.

Desde este punto de vista, los guaraníes llegados a las faldas de los Andes bolivianos en aquellas siete invasiones serían los antecesores de los "modernos" chiriguanos cuyo grado de andinización resultaba fortificado por el puente que establecía un pueblo arawae que los españoles encontraron como siervos de nuestros Chriguanos: los chané. Además la información etnográfica avalaba este raciocinio. Metraux encontró que Chichas y Chané compartían vestidura y cerámica (Metraux 1963: 467).

Cabe señalar que a pesar de que la descripción de esta tribu permaneciera casi invariable desde los primeros españoles, no han faltado comentarios marginales de quienes, aun participando del esquema de los cronistas, anotaban algunas incongruencias inexplicables en esta diáfana pintura de bárbaros y civilizados. El mismo barón de Nordenskiöld se preguntaba como apenas mil chiriguanos causaron tantos problemas al Imperio de los Incas (Nordenskiöld 1917: 115-116). También debió sorprender el hecho de que la misma fortaleza de Cuzco-tuyo (Cuzco-toro en Ruy Díaz) construida por los incas para defensa de su imperio resultó luego el baluarte de los Chiriguanos contra los españoles (Díaz de Guzmán 1962: 36 y 244) y que incluso sean los propios Chiriguanos quie- 
nes conservan un remedo de la pompa cuzqueña ya bien entrada la Colonia (Gandía 1929: 111).

Conforme se avanza en la confrontación de las fuentes las contradicciones de nuestro divulgado cuadro general se agudizan. Al Inca Yupanqui de Garcilaso se suman: Manco Capac (Montesino 1930: 15-16), Huaina Capac (Morúa 1946: 99-100) Sinchi Roca (Montesinos 1930: 98) como presuntos salvadores de la amenaza chiriguana, lo que hace pensar, que antes que de una fecha, los informantes indígenas están hablando de un concepto que representa lo exterior y extraño al Tahuantinsuyo. Ello no invalida el hecho histórico concreto que pudo haber existido al mismo tiempo pero que se tiene que entender en un plano totalmente diferente. En las líneas que siguen vamos a tratar de explicar esta aparente superposición con situaciones paralelas.

Los incas llamaron antis a todos los invasores del Este y sus definiciones acerca de lo que la selva representa para el serrano, es hoy un dato etnográfico que puede recogerse en las calles de Lima. Fernando Romero en sus Cuentos de la Selva resumió perfectamente el sentir popular que arrastraba una idea del mundo conocido, el ingreso a ella lleva consigo el riesgo de la aventura incierta y precaria. Igual hacia el norte, los gigantes homosexuales de Santa Elena (Garcilaso 1960: tomo III 193) fueron exterminados gracias al fuego divino y con ellos el peligro del otro extremo del Tahuantinsuyo; su presencia justificaba el límite del imperio: más allá de los lindes que pusieran los cuzqueños quedaba lo ignorado y lo extraño. Para el Sud-oeste el peligro eran los chiriguanos, no en vano habían recibido similar castigo que los gigantes de Santa Elena por el mismo pecado (Mora 1931: 115). Esto significa que cuando los documentos coloniales hablan de Chiriguanos como concepto de frontera y peligro del sud-este cuzqueño y la tribu que los españoles encontraron en las viejas construcciones de Cuzco-toro y cuya independencia y valor hizo desistir a más de un virrey en los intentos de "pacificación" de la zona. Años atrás quedaban los intentos de colonizar esas áreas donde Andrés Manso y Ñuflo de Chávez habían hecho sus precarias fundaciones (Vargas Ugarte 1949: 128).

\section{LOS CHIRIGUANOS A PARTIR DE SUS PROPIAS FUENTES}

En adelante intentaremos presentar el problema desde una perspectiva chiriguana. Ya sabemos cómo incluso estudiosos de calidad cayeron en la trampa que presenta la armoniosa documentación quechua. No dudamos que exista igual información acerca de los chiriguanos pero todavía no ha sido lo suficientemente divulgada como quebrar la organizada imagen que presentan las culturas andinas.

Atacaremos el problema desde el mismo ángulo en que se sustenta la versión quechua: las migraciones. En un excelente libro ya la Profesora Pereira de Quiroz ha probado (1965) cuando menos dos constantes en las migraciones mesiánicas de los indios del Brasil: una corriente al Este en busca de la "tierra sin males" y otra al oeste persiguiendo los rumores que suscitaba la presencia del Tahuantinsuyo. No creo arriesgado afirmar que para los primitivos guaraní funcionara la misma idea; el camino del sol, también seguido por los caduceo (Boggiani 1894) y la necesidad de metal pudo repartir por lo menos en ambas direcciones distintos tipos de recorrido. Y así para los Mbayá se calcula 1000 d. C. como inicio de sus migraciones no pienso que fueran más tardías las que impulsaron a los futuros Chiriguanos hacia el oeste. Convendría cotejar los hallazgos de Ibarra Grasso (1965: 195-201) en Mizque, área ocupada por el chiriguanos en tiempos históricos, con los grabados y tipología de Outes (1909: planchas I y II) o las excelentes reproducciones de Metraux (1929), en todo caso las implicaciones sugeridas con la costa peruana (nazcoide) no dejan de ser sugestivas. Por desgracia el arqueólogo boliviano no presenta una documentación gráfica suficiente para dicha comparación.

Hubo, pues, una larga ocupación de los corregimientos de Mizque, Tomina, Paspaya y Tarija entre las cordilleras oriental y central de Bolivia (Díaz de Guzmán 1962: 26); ya Nordenskiöld (1917: 120), revisando Matienzo pudo encontrar la lejana referencia de las gentes de Tarija arrojadas por los Chiriguanos mucho tiempo atrás, hecho que encaja con los movimientos generales de los tupi-guaraní correspondientes al Invasionist Stage sugerido por Lathrap (1962: 
567). Parece sintomático que esto coincidiera con el desplazamiento del Tawantinsuyo hacia el norte y el acrecentamiento de poder en los jefes andinos del Collao. En última instancia, fueron ellos los que detuvieron el progreso de las invasiones hispano-guaraní (Díaz de Guzmán 1962: 36-38), su creciente independencia del poder cuzqueño cada vez más concentrado en la región de Quito también se puede probar a través del documento de Chuquito que publicara Murra en 1964.

El establecimiento del Virreinato del Perú y la Audiencia de Charcas que acabó con el poder político de las culturas andinas encontró en cambio una porfiada resistencia en los Chiriguanos. Desde 1557 Ruy Díaz (1962: 205) registra el levantamiento del profeta Cutiguará y son múltiples las referencias que ligan a este pueblo con los rebeldes incas de Vicabamba (Maúrtua 1906 Tomo II 48 y 92; Gandía 1929: 131 y 137$)$

Entre 1726 y 1727 un nuevo jefe, Aruma, subleva su gente contra los españoles que triunfan a duras penas apoyándose en los indios Chiquitos que actúan como aliados (Metraux 1963: 467; Gandía 1929: 55). Medio siglo más tarde un extraordinario movimiento documentado por Metraux (1931: 81-85) conmovió las misiones de Manabí, Zaypurá, Tapuyta, Tacuru y Aguayrenda en la hoya del río Grande. El "Dios Fingido" y sus emisarios obligaron a una masacre sistemática por parte del gobernador de Santa Cruz.

La llegada de la llamada emancipación latino-americana no cambió el cuadro hasta ahora presentado. En 1886 un nuevo profeta que se hace llamar "Chiriguano" se rebeló contra el gobierno boliviano (Metraux 1963: 468). Sólo la guerra del Chaco que cogió entre dos fuegos a los sobrevivientes de esta tribu parece haber acabado con su vitalidad; el cuadro dantesco del fusilamiento de un indio "desertor" (Céspedes 1933: 116-117) explica su masiva migración hacia Argentina.

Si dejamos aparte el dato histórico tenemos que reconocer que el relato de esta constante revolucionaria de los chiriguanos ha dejado una excelente documentación etnográfica. Ya los mismos españoles se preguntaban cómo destruir a un enemigo que no presentaba batalla sino que atacaba en pequeñas partidas y que luego de un rápido asalto se retiraban sin dejar tiempo a un combate formal. Tanto es así que la campaña de 1729 -de la que tenemos un detallado relato- fue realmente llevada a cabo por los indios Chiquitos que reconocen tener una antigua rivalidad con los Chiriguanos y se prestan como aliados de los españoles. Ellos van a servir especialmente en la ubicación de las aldeas así como en el asalto de las empalizadas reforzadas con plantas espinosas con que las protegían (Mora 1931: 121, 122, 126). Ante los europeos los Chiquitos se vanaglorian de haber empalado a los chiriguanos en tiempos pre-hispánicos y del terror que inspira el veneno de las flechas (Mora 1931: 109). Ya para esta fecha los chiriguanos han sido constreñidos casi a los límites actuales: Guacara, al borde de la actual provincia de Tarija en uno de sus últimos baluartes (Mora 1931: 107); hace ya más de un siglo que la constante persecución de los Gobernadores de Santa Cruz de la Sierra los va empujando hacia el sur. En su fuga y bajo la presión de los enemigos nativos y europeos los Chiriguanos descubren rasgos de una Tropical Forest Cultura: sus flash-and-burn sirven de pista a sus perseguidores quienes aprenden que los campos "quemados" (que tenían) eran muestras de querer sembrar cuando los españoles se retirasen (Mora 1931: 120). Incluso su fuga es sostenida por la mangana (Mora 1931: 119) una papa silvestre que parece haber sido reconocida por Levi-Strauss bajo el nombre de mandioquinha de campo (1950: 479) y que los chiriguanos utilizaban como alimentación de emergencia.

No tenemos elementos de juicio para discutir el origen andino (Metraux 1963: 481) del pito guerrero con que prevenía o empezaba un ataque, en todo caso no aparece mencionado como tal nombre en la documentación quechua o aymara que conocemos. A juzgar por los cronistas de esa parte del continente son otros los instrumentos musicales que acompanaban al combate.

\section{Algunas notas sobre los Chiriguanos CON- TEMPORÁNEOS}

Perseguidos o no los Chiriguanos se dieron maña para ser constante peligro hasta la época republicana. Justamente, la falta de informa- 
ción a partir de la década del 40 nos impide observar con claridad los últimos cambios de esta tribu. Algo podemos inferir del trabajo de Palavecino (1949: 117-119) aunque sus notas fueron tomadas en función del grupo Chané a quienes dedica su estudio. Aclaremos además que sólo visitó el Chaco salteño y que la información deriva de cuatro viajes cortos más bien dedicados a conseguir una colección de máscaras, pero al menos de una perspectiva post-guerra del Chaco que debió ser importante para el complejo Chiriguano-Chané.

No es esta la oportunidad de examinar a los Chané, a nosotros nos sorprendió la temprana información de Núñez Cabeza de Vaca que los observó libres de toda dominación y como excelentes cultivadores de "maíz y mandioca y batatas y mandubias en mucha abundancia" (1922: 288). Hubiese sido interesante observar las actuales relaciones entre ambos grupos. Líneas arriba aludí a la relación Cubeo - maca (también excelentemente expresada en Desana por Reichel-Dolmatoff) como ángulo de comparación que debemos tomar para entender esta dependencia. Incluso, pienso que el caso de los uros del altiplano y la institución de los yanaconas incaicos tendrían que revisarse en una misma línea. Hoy día se aprecia que los jefes chiriguanos tienen ya sirvientes personales (Metraux 1963: 478), me gustaría poder averiguar si ello se debe a una evolución del sistema de dependencia o simplemente al contrato europeo.

Una excelente observación que sí realizó Palavecino (1949: láminas II y III) fue la del carnaval, y las máscaras que le recuerdan motivos amazónicos. Justamente, fue durante el carnaval donde el antropólogo argentino observó la danza del tigre y del toro a la que convendría un análisis cuidadoso en tanto que se trata del drama final de dicha fiesta en Tuyunti, uno de los últimos refugios Chané que aun se puede visitar. Con los dos bailarines se alude a una antigua tradición pre-hispánica en la que el felino ahora enfrenta a una transposición en el personaje del toro probablemente relacionado con la luna que termina por ser abatido (Palavecino 1949: 131).

Esta contienda es un motivo constante en la mitología Chiriguana: el tigre devora a la luna. El eclipse interpretado de esa forma es parte de todo un gigantesco ciclo mítico -los mellizos- cuyas diferentes versiones recogiera Metraux (1932: 135-151). Aquello que definitivamente lo confunde en la existencia de versiones andinas para diversas partes de este ciclo: "si atribuimos un origen andino a este mito, tenemos al mismo tiempo que colocar el centro de dispersión de los tupí-guaraní en la cercanía de la región andina, lo que está en contradicción con los hechos etnográficos conocidos hasta la fecha" (Metraux 1932: 133).

Sin embargo, la versión peruana no era precisamente de la Sierra, Metraux la recogió de Ávila que tomó sus relatos a corta distancia de la costa, en Huarochirí (hoy departamento de Lima). En esta versión se describe un eclipse durante el cual los objetos se sublevan contra los hombres, es decir, se invierte el orden del mundo marcando el inicio de una nueva era. Los gritos y ruidos con que se evita este trastorno ha sido motivo de observación en las tolderías chiriguanas en los documentos coloniales sobre el área andina. Más adelante Metraux completa el mito de los mellizos con otra versión recogida en Huamachuco, provincia situada en la sierra nor-peruana.

No entraremos a detallar las diferentes variantes de todo el mito, existen ya excelentes trabajos buscando las correcciones de mismo hasta con la que aparece en el Popol-Vuh (Imbelloni 1960), lo que nos interesa es la dispersión del mismo en Sudamérica que Metraux resumió en un pequeño mapa, de acuerdo con él, de las quince versiones existentes, ocho son tupí-guaraní y aparte de la quechua registra aquellas de los turacare, bakairi, kaingang, warrau, kirib, jíbaro y amuesha. Páginas adelante en el análisis de otro mito de origen bastante menos difundido Metraux acepta su prodecencia andina: "su centro de difusión se halla seguramente en el oeste del continente puesto que en las regiones orientales su dispersión parece limitarse a 2 tribus tupí-guaraní, que sin duda alguna han recibido este mito al mismo tiempo que otros elementos andinos" (Metraux 1932: 168).

No es ésta nuestra opinión, sagazmente Tello había llegado a insinuar conclusiones opuestas usando los mismos materiales (Tello 
1923: 93-320 y 583-606), donde la presencia del tatú y del zorro se hacen congruentes con el hábitat donde el mito hace figurar las acciones.

No pretendo finalizar aquí y ahora este trabajo, de hecho su estudio necesita también el conocimiento de grupos vecinos cuya importancia sea evidente como el de los chichas. Cuya zona fuera la puerta de entrada a los Andes en las pretendidas invasiones, o los diaguitas y omeguas que combatieron al lado de nuestros Chiriguanos contra los españoles.

Pero al lado de esto es indispensable el manejo de las materiales que usaron y usan la gente de esta tribu.

No obstante, el uso de un nuevo esquema para el conocimiento de la historia cultural de Sudamérica ayudará a no repetir su versión tradicional e iniciar las bases de una reinterpretación de la información conocida y la búsqueda de nuevas fuentes.

\section{BibliografíA}

Anello Oliva, Giovanni

1895 Historia del reino y provincias del Perú de sus reyes incas descubrimiento y conquista por los españoles de la corona de Castilla con otras singularidades concernientes a la historia. Imprenta y Librería de San Pedro, Lima.

Boggiani, Guido

1894 Viaggi d'un artista nell'America Meridionale / Caduvei (Mbayá o Guaycuru). Ermanno Loescher \& Co Roma

Céspedes, Augusto

s/f Relatos de la Guerra del Chaco. Populibros Peruanos S.A. Lima

Díaz de Guzmán, Ruy

1962 La Argentina. Angel Estrada y Cía S.A. Editores. Buenos Aires.

Gandía, Enrique de

1929 Historia del Gran Chaco. Juan Roldán y Cía. Madrid.

Garcilaso de la Vega, Inca

1960 Comentarios Reales de los Incas. UNMSM. Lima

Goldman, Irving

1966 The Cubeo Indians of the Northwest Amazon.
The University of Illinois Press. Illinois.

Ibarra Grasso, Dick Edgar

1965 Prehistoria de Bolivia. Editorial Los Amigos del Libro. La Paz.

Imbelloni, José

1960 Civitá Andina. Casa Editrice Sansone. Florencia.

Lathrap, Donald

1962 Yarinacocha: stratigraphics excavations in the Peruvian Montaña. Ph.D. thesis. Harvard University. Cambridge.

Lehmann-Nitsche, Ricardo

1925 "La astronomía de los Chiriguanos". Revista del Museo de la Plata, tomo XXVIII (tercera serie, tomo IV). Buenos Aires.

Leví-Strauss, Claude

1950 "The use of the wild plants in tropical South America". Handbook of South American Indians. Vol. 5, Julian H. Steward. Editor. Washington.

Maúrtua, Víctor M.

1906 Juicio de límites entre Perú y Bolivia. Prueba peruana presentada al gobierno de la República. Imprenta de Henrich y Comp. Barcelona.

Means, Philip Ainsworth

1917 "A note of the Guarani invasion of the Inca empire". The Geographical Review, vol IV. July-December.

Metraux, Alfred

1929 "Etudes sur la civilisation des Indiens Chriguano". Revista del Instituto de Etnología de la Universidad Nacional de Tucumán, tomo I.

1931 "Les hommes-diex chez les chiriguano et dans l'amerique du Sud". Revista del Instituto de Etnología de la Universisdad de Tucumán, tomo II.

1632 "Mitos y cuentos de los indios chiriguanos". Revista del Museo de la Plata. Tomo XXXIII (tercera serie, tomo IX). Buenos Aires.

1963 "The Guarani". Handbook of South American Indians, vol. 3. Julian H. Steward, New York.

Montesinos, Fernando de

1930 Memorias antiguas historiales y políticas del Perú. Librería e Imprenta Gil. Lima.

Mora, Bartolomé de

"Relación y breve noticia de lo sucedido en la guerra de chiriguanos que se ha hecho este año de 1729 por orden del señor Virrey y real audiencia de Charcas (Chuquisaca)". Revista del Instituto de Etnología 
del a Universidad Nacional de Tucumán, Tomo II.

Murra, John Victor

1968 "An Aymara kingdom in 1567". Ethnohistory, volumen 15 , number 2, spring, Buffalo

Murúa, Martín de

1946 Historia y genealogía real de los reyes incas del Perú. Consejo Superior de Investigaciones Científicas. Madrid.

Nordenskiöld, Erland

1917 "The Guarani invasion of the Inca empire in the 25 sixteenth century: an historical indian migration". The American Geographical Society, July-Dec.

Núñez Cabeza de Vaca, Álvar

1922 Naufragios y cometarios. Calpe editores. Madrid.

Outes, Félix F.

1909 "La cerámica Chiriguana". Revista del Museo de la Plata, tomo XVI (serie segunda, tomo II) Buenos Aires.

Palavecino, E.

1949 "Algunas informaciones de introducción a un estudio de los chané". Revista del Museo de La Plata (Nueva Serie). Tomo IV. La Plata.
Pereira de Queiroz, María Isaura

1965 Omesianismo no Brasil no mundo. Mominus editora S. A. Sao Paulo.

Pericot y García, Luis

1962 América Indígena, tomo I. Salvat editores. Barcelona.

Sarmiento de Gamboa, Pedro

1947 Historia de los Incas. Emecé editores S.A. Buenos Aires.

Serrano, Antonio

1947 Los aborígenes argentinos. Editorial Nova. Buenos Aires.

Tello, Julio C.

1928 "Wiracocha”. Revista Inca. Tomo I.

Vargas Ugarte, Rubén

1949 Historia del Perú / Virreynato (1551-1600). Talleres Gráficos de A. Baiocco y Cía. Lima

Vasques de Espinosa, Antonio

1948 Compendio y descripción de las Indias Occidentales. The Smithsonian Institution, Washington. 